\title{
A simple model for post-landfall intensity changes of tropical cyclone over India, Bangladesh and Myanmar coasts
}

\author{
C M Kishtawal, Shivani Shah*, Sashmita Chaurasia and Neeru Jaiswal \\ Atmospheric and Oceanic Sciences Group, EPSA, Space Applications Centre, Ahmedabad 380 015, India. \\ ${ }^{*}$ Corresponding author. e-mail: shivanishah@sac.isro.gov.in
}

Using JTWC (Joint Typhoon Warning Center) best track analysis data for the Indian Ocean cyclones, we developed an empirical equation for prediction of maximum surface wind speed of tropical cyclones during first 6-12 hours of landfall along the coastline of Indian subcontinent. A non-linear data fitting approach, the Genetic Algorithm, has been used to develop the above empirical equation using data for 74 tropical cyclones that made landfall on the coasts of India, Bangladesh and Myanmar during the period 1978-2011. For an out of sample validation test, the mean absolute error of the prediction was found to be $5.2 \mathrm{kt}$, and a correlation of 0.97. Our analysis indicates that time-integration of land area intercepted by cyclones during the landfall is a better predictor of post-landfall intensity compared to post-landfall time span. This approach also helps to tackle the complexity of coastline geometry of Indian subcontinent area.

\section{Introduction}

While the prediction of cyclone track has improved considerably during the past few decades mainly due to advances in NWP modelling and data assimilation research, the skill of prediction of tropical cyclone intensity has not improved much (Bender et al. 1993). Tropical systems weaken rapidly after landfall due to lack of surface moisture fluxes (Emanuel 1991; Kaplan and DeMaria 1995). Heterogeneities in the landscape features (e.g., in soil moisture, surface roughness, albedo, vegetated land cover) can create mesoscale boundaries that can impact regional circulation, convection and precipitation (Pielke 2001; Wong and Chan 2006; Pielke and Niyogi 2009). Development of numerical or empirical models that can accurately predict tropical cyclone intensity after landfall has significant socio-economic importance (Marks et al. 1998). Besides real-time operational applications, such models can be helpful for stochastic simulation of the cyclone-related risk in coastal regions, which in turn helps in designing buildings and structures that can withstand the impact of land falling cyclones (Vickery et al. 2008). Moreover, understanding of the nature of post-landfall cyclone decay using observed data can be helpful to make improvements in NWP models to enhance their skill for intensity prediction. There have been continued attempts to develop and improve the models for prediction of post-landfall intensity changes over the US coast (Vickery 2005; DeMaria et al. 2006). However, there have been limited attempts to analyze the nature of post-landfall cyclone intensity changes over the Indian subcontinent region (Bhowmik et al. 2005), despite the fact that these regions are among the most densely populated places on earth and highly vulnerable to tropical cyclone risk. In the present study, we used observed data of maximum

Keywords. Post-landfall intensity; genetic algorithm; probability; TC decay rate. 
sustained surface winds for a large number of tropical cyclones to develop a generalized empirical equation that can be helpful in predicting postlandfall cyclone intensity changes over the coasts of India, Bangladesh and Myanmar. These coasts have historically witnessed the most catastrophic cyclone-related disasters in terms of human deaths. Indian subcontinent has uneven coastal geometry and highly variable land type due to which it is a challenge to develop a single and skillful decay model that can be applicable to the entire coastline. We tried to tackle the above problem by

- using a data-adaptive model fitting algorithm, which is capable of discovering functional relationships between response variable and predictors, based only on the data. This approach eliminates the need to assume the nature of the post-landfall decay (e.g., as exponential function of time, etc.), and thus allows higher flexibility to model-building process. As a result, the empirical models so develop often show lower errors and explain higher amount of variability of modelled process.

- Introducing the concept of 'landfill-factor', which is the area of land intercepted by a moving circular object of pre-determined area. Coastal region of Indian subcontinent consists of discharge basins of some of the large rivers like Ganga, Brahmputra, etc., with large deltas. Factors like river water availability, high amount of soil moisture and complex shapes of terrain and coastline, impact the post-landfall intensity of tropical cyclones (Tuleya 1994; DeMaria et al. 2006; Chang et al. 2009; Pielke and Niyogi 2009). Since the process of decay of tropical cyclones is critically linked to lack of moisture and heat fluxes from the underlying surface (Emanuel 1991; Tuleya 1994), it is necessary to correctly estimate how much area of cyclone core is actually over land during the crossing of coastline. High resolution maps of land-ocean surface types can be helpful to make the first order or preliminary estimates of the portion of land likely to be intercepted by cyclone in these complex terrains.

\section{Data and methods}

\subsection{Tropical cyclone track and intensity data}

The observations for cyclone track and intensities were sourced from the Joint Typhoon Warning Center (JTWC) that maintains an archive of tropical cyclone track data, commonly referred to as 'best-tracks'. Each best-track file contains tropical cyclone center locations and intensities (i.e., the maximum 1-minute mean sustained $10 \mathrm{~m}$ wind speed) at 6-hour intervals (Chu et al. 2002). Even though the track positions for the Indian Ocean cyclones were available since 1945, continuous observations of cyclone intensities are available only after the year 1978. Data for 74 cyclones that made landfall over the Indian subcontinent coastline during the pre-monsoon (January-May) and post-monsoon (October-December) cyclone seasons for the period 1978-2011 were used for the study. Figure 1 shows the location of these cyclones before and after crossing the coastline. It is easy to see that our dataset contains a uniform distribution of the landfalling cyclones, particularly over the eastern part of the Indian Ocean. Over the western coasts, the climatological probability of cyclone landfalls is significantly smaller. Moreover, the present dataset covers a wide spectrum of pre-landfall cyclone intensities from tropical deep depressions to super cyclones (figure 2). Post-landfall intensity change for majority of the cyclones within first 6 hours is $10-15 \mathrm{kt}$, however an intensity change of $50-60 \mathrm{kt}$ is also indicated by the present dataset.

Landfall locations of the tropical cyclones from 6 -hourly best track data were determined by considering the Indian subcontinent coastline as a polygon and then solving the 'point-in-polygon' problem to calculate the first inland location of cyclones. Using the last on-shore position and first in-land locations of cyclone (separated by 6 -hours

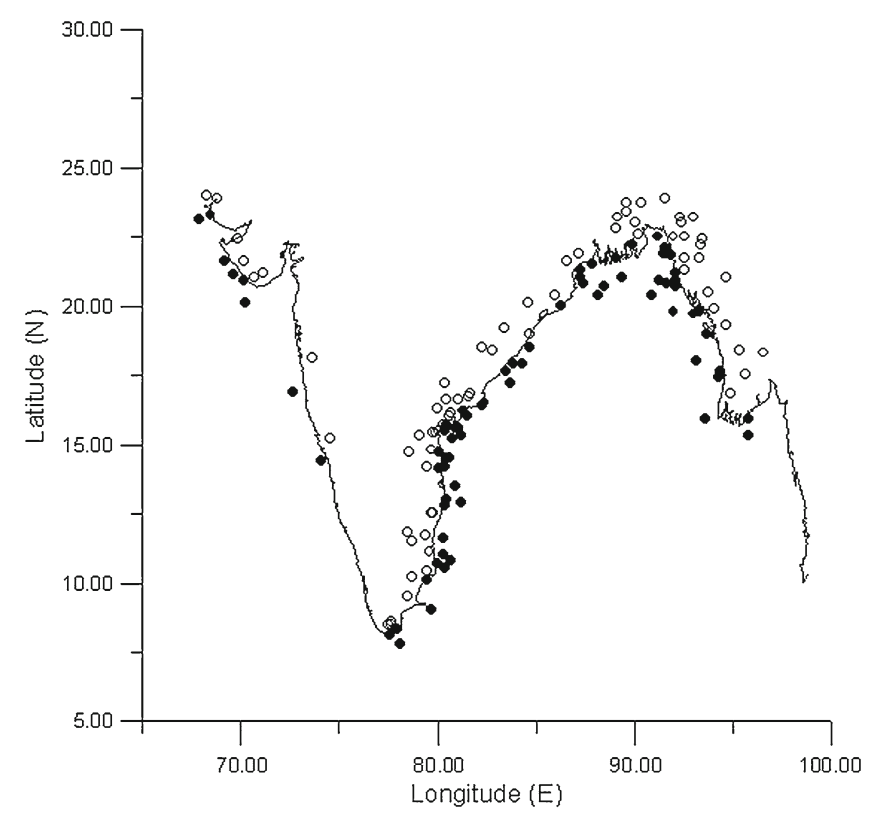

Figure 1. Locations of landfall by cyclones considered for the present analysis. Dark circles denote pre-landfall locations while open circles denote locations within first 12 hours of landfall. 
in time), the exact position and time of landcrossing were determined, assuming that the translation speed of cyclone was constant for this 6-hour period. This exact crossing-point was used to compute the post-landfall time. If post-landfall time was found to be less than 2 hours, then next inland point was considered to be the post-landfall location of cyclone. The values of cyclone intensity at last on-shore locations were used as 'initial' values of the cyclone intensity in the model.
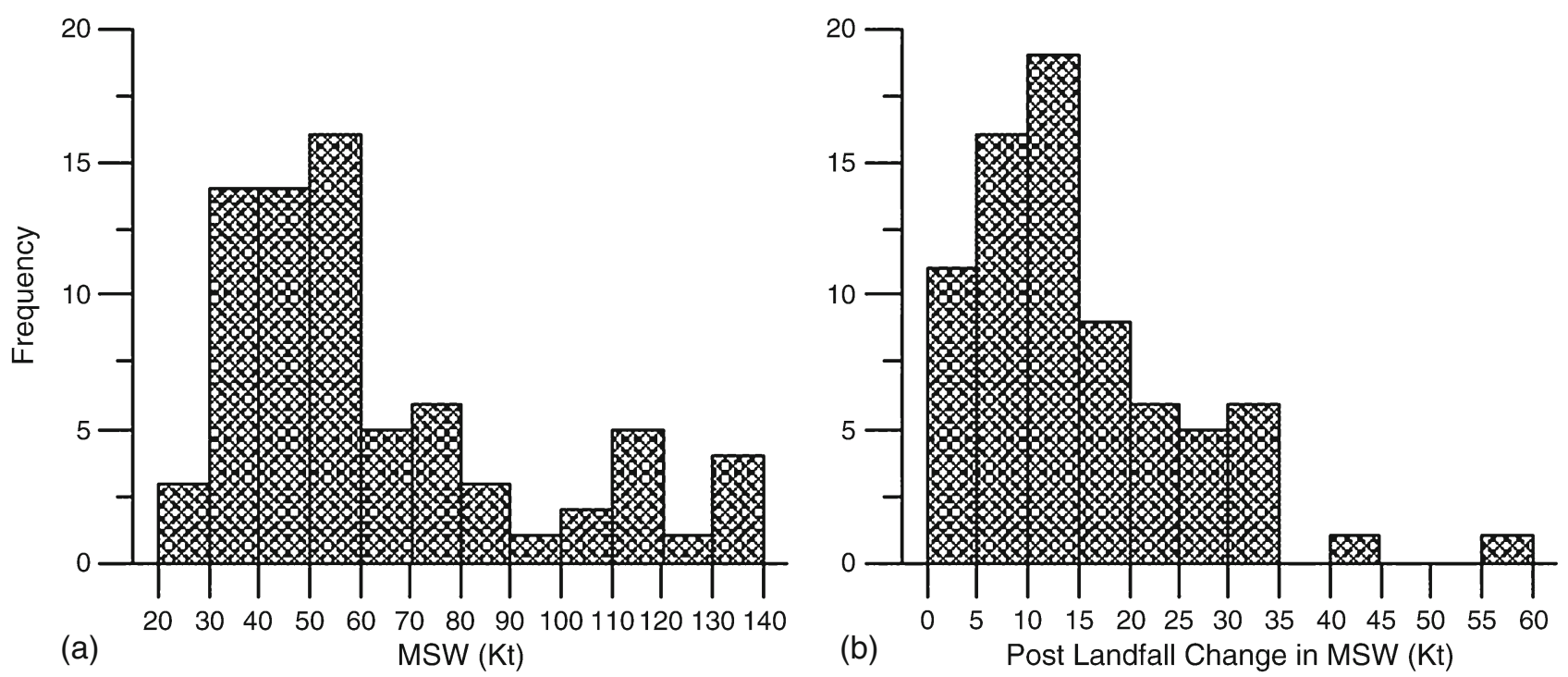

Figure 2. Histograms of (a) pre-landfall intensities (denoted by MSW in kts) of cyclones used in present analysis and (b) post-landfall intensity change $(\mathrm{kt})$.
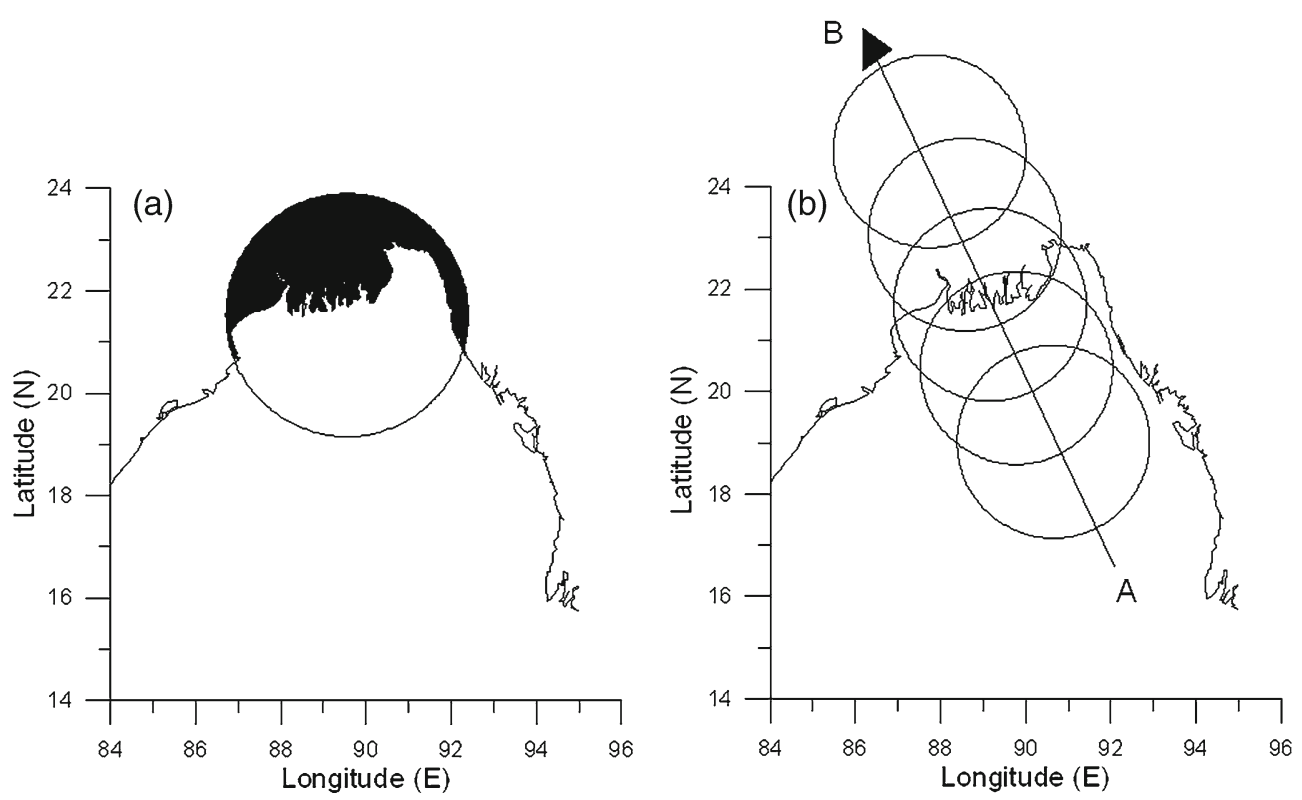

Figure 3. (a) Part of Bangladesh coastline and a simple concept of 'landfill factor' and (b) schematics showing computation of 'integrated landfill factor' (ILF), which is integration of fractional land area within different circles of $200 \mathrm{~km}$ diameter. Each circle is centered at 6-minute time interval between offshore point (where initial intensity is known) and the inland point (where the post-landfall intensity is to be predicted). 


\subsection{The 'landfill factor'}

Some portions of the Indian subcontinent have complex coastline geometry. One such coastline of Sundarban delta in the Bay of Bengal is depicted in figure 3(a). Obviously, the cyclone intensity decay process over such surfaces cannot be same as one over a uniform surface. In order to tackle issue of surface inhomogeneities, we introduce the concept of 'landfill-factor' or LF, which is the fraction of land area within a circle (which is an approximation of the shape of the cyclone core) intercepting the underlying surface at a given time. ETOPO30 land-water mask data, available at $0.00833^{\circ}$ lat./long. spatial resolution, was used to compute $\mathrm{LF}$ at each 6-minute time interval, linearly interpolated between the last off-shore location (point $\mathrm{A}$ in figure $3 \mathrm{~b}$ ) and the inland-location (point-B) of the cyclone. These LFs were then added to get integrated LF or ILF, and was used as a predictor in our analysis. Ideally, the size of the circle in LF computations should vary from cyclone to cyclone, but reliable observations of cyclone size parameters are rarely available in the best track analysis. Hence, we experimented with different values of the size of the circle and found that an assumption of $\sim 200 \mathrm{~km}$ diameter leads to most stable results.

\subsection{Empirical model development and model selection criteria}

We used Genetic Algorithms (GA) to derive empirical functions that explain the post-landfall cyclone intensity in terms of initial intensity, post-landfall time span and cyclone structural parameters. GA is a search heuristic that mimics the process of natural evolution such as inheritance, mutation, selection, and crossover. This heuristic is routinely used to generate useful solutions to optimization and search problems. A detailed description of the GA technique used for the present study can be found in Alvarez et al. (2001). The major advantage of GA for function fitting is its complete data adaptability in which no a-priori assumption of the form of the function is needed to build a solution. GA procedure often results in unexpected forms of fitted function, which sometimes may help in understanding the nature of the process under study.

A preliminary selection of predictors was made based on the findings of earlier researchers, e.g., Kaplan and DeMaria (1995); Vickery (2005) and Colette et al. (2010). Ho et al. (1987) noted that the TC decay rate is proportional to initial intensity and that the decay rate is highest immediately after the landfall. Figure 4 shows a strong correlation between 'average' values of post-landfall intensity changes and pre-landfall storm intensity for Indian Ocean cyclones. Thus initial, pre-landfall

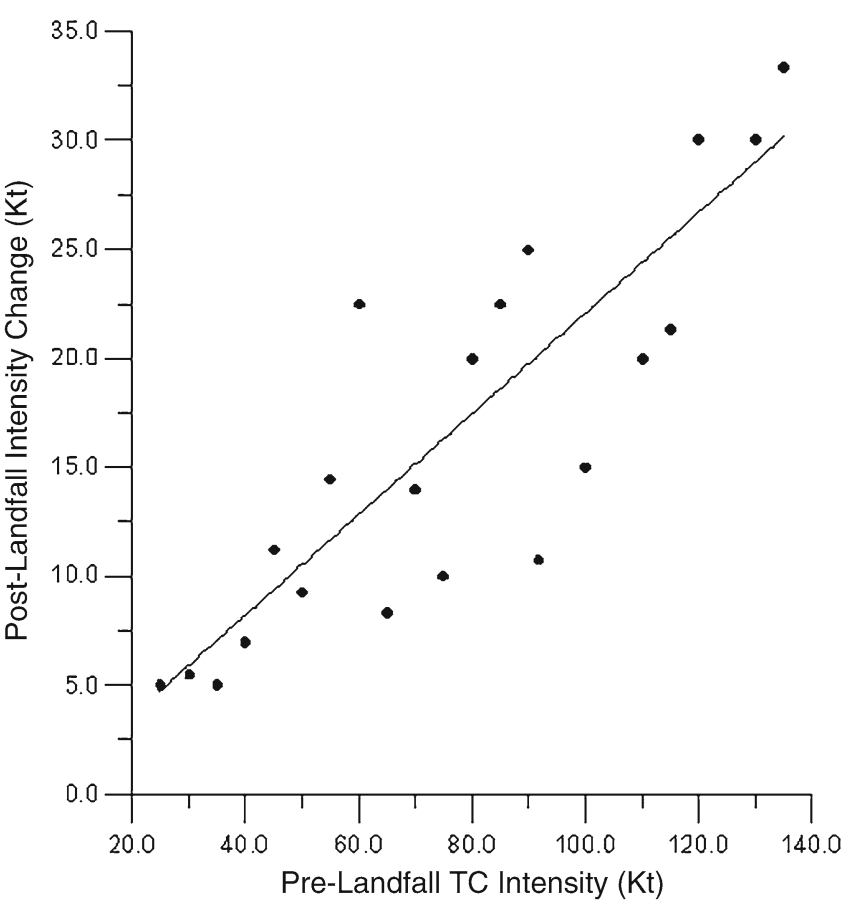

Figure 4. Variation of average change in TC intensity after landfall for cyclones of different pre-landfall intensities over the Indian Ocean. The figure is based on the same dataset that is used for model development.

intensity and post-landfall time span were the natural choice of predictors. We integrated landfillfactor, ILF, as additional predictor. Almost all the above notable empirical decay models assume exponential decay of cyclone intensity after landfall. In the present study we developed two types of empirical models, one with forced exponential behaviour, and another without any assumption of the form. In terms of response variables and predictors, the models were developed in the following manner:

(A) Exponential model:

$$
\log \left(\mathrm{MSW}_{\mathrm{L}}\right)=f\left\{\log \left(\mathrm{MSW}_{\mathrm{o}}\right),(t \text { or ILF }), c\right\}
$$

and

(B) Freeform model:

$$
\mathrm{MSW}_{\mathrm{L}}=g\left\{\mathrm{MSW}_{\mathrm{o}},(t \text { or ILF }), c\right\}
$$

where $f$ and $g$ are the functions that best define the relationship in the equation within the range of the given data, $\mathrm{MSW}_{\mathrm{o}}$, and $\mathrm{MSW}_{\mathrm{L}}$ denote the initial (before landfall) and post-landfall maximum winds, $t$ is time, IFL is integrated landfill factor, and $c$ is the translation speed of the cyclone. Since ILF is integrated over time, it implicitly contains the information of time. In our model-development procedure, we used either $t$ or ILF but not both in the same equation. The GA process in the present 
study tends to maximize a 'fitness index' $R$ in an iterative manner to develop the functions, where $R$ is defined as:

$$
R^{2}=1-\left[\Delta^{2} / \sum\left(x_{\mathrm{o}}-\left\langle x_{\mathrm{o}}\right\rangle\right)^{2}\right]
$$

where $\Delta^{2}=\sum\left(x_{\mathrm{c}}-x_{\mathrm{o}}\right)^{2}, x_{\mathrm{c}}$ is parameter value estimated by the best scoring equation, $x_{\mathrm{o}}$ is the corresponding 'true' value, and $\left\langle x_{\mathrm{o}}\right\rangle$ is the mean of the 'true' values of $x$. Before initiating the GA process, the data-rows containing response variable (predicted intensity) and the set of predictors were randomly shuffled and only first 57 of 74 rows were used for model development. Remaining 17 rows were used for out-of-sample validation test as a measure of reliability of the model skill. The GA process is initialized with a number of random solutions (functions represented by character strings), called the initial population. The final solution emerges after a long iterative evolutionary procedure consisting of crossover (in which high scoring solutions exchange their features to produce new solutions) and mutation (in which some individual solutions are randomly modified). Since the GA procedure uses so many random processes, it is very difficult to ensure that the final solution is globally optimum, or the best possible solution. In order to obtain the best possible function for our purpose, we integrated the GA process several times by perturbing the control parameters of the GA process to develop equations for models denoted by equations (1-3). The perturbed control parameters were:

- 5 different random seeds to generate initial random population

- size of initial population from 400 to 800 (in steps of 100) for each seed

- probability of mutation from 0.1 to 0.3 in steps of 0.1 , and

- maximum size of final equation from 10 to 14 terms (including predictors and mathematical operators) in steps of 2 .

This results in generation of 225 different solutions for each of the models. Preliminary selection of the best model was done using the Akaike Information Criteria (AIC). Significant emphasis has been placed on the criteria for model selection in recent statistical literature. Based on Akaike's (1974) original model-selection criteria, many model-selection procedures which take the form of a penalized likelihood (negative log likelihood plus a penalty term) have been proposed (Sclove 1987). For example, for AIC, this form is given by

$$
\mathrm{AIC}=-2 \log L(\theta)+2 k
$$

where $L(\theta)$ is the maximized likelihood function, and $k$ is the number of independent parameters in the model. The model with minimum AIC value is chosen as the best model to fit the data. Next step is to test the best model for the 'continuity' using an artificial set of data in which the value of predictors is extended beyond the range that is available in the training data. It is important to ensure that the model remains stable within plausible values of predictors even if such values were not encountered during the model development. If the best model fails the criteria, the lower ranking models are tried for the continuity test, and taken as the best models if they succeeded.

\section{Results}

The key questions that we tried to resolve in our model-building exercise are:

- whether decay models of exponential form or free form provide better prediction of cyclone inland decay, and

- whether post-landfall time or integrated landfill factor is a better predictor in the above equations.

To answer the above question, we tried to develop four types of equations, two in exponential form and two in free form. In each category, in addition to initial intensity, $\mathrm{MSW}_{\mathrm{o}}$ and cyclone motion speed $c$, we used either time or ILF as third predictor. Various combinations of GA configurations, as mentioned earlier, were used to develop 225 different equations for each experiment. Only those equations for which AIC was less than 305.0 were examined for further analysis. This value of AIC leads to filtering and rejection of approximately $90 \%$ of the models.

\subsection{Freeform models}

For freeform model with predictor set $\left\{\mathrm{MSW}_{\mathrm{o}}, t\right.$, $c\}, 35$ equations satisfied the AIC threshold, and only three of these 35 models selected $t$ as potential predictor, while $\mathrm{MSW}_{\mathrm{o}}$ and $c$ were selected by every model. This indicates that the cyclone decay process within first few hours is nearly independent of time and depends more on factors like speed of storm. The AIC score achieved by the best model was 295.0, and the best prediction accuracy (mean absolute error) was $5.76 \mathrm{kt}$. For 11 cases out of 75 , the prediction error was found to exceed $10 \mathrm{kt}$. Interestingly for the best model, the decayed intensity was not a function of time. When we replaced $t$ by ILF in freeform set-up, the GA process resulted in 37 models that satisfied AIC threshold, all but two of which selected all three predictors $\left\{\mathrm{MSW}_{\mathrm{o}}\right.$, ILF, $c\}$. The AIC score of the best model was 284.5, 
and the prediction accuracy was 5.42 kt. Maximum error (20.45 kt) and the number of cases with prediction error $>10 \mathrm{kt}$ were also reduced to 7 .

\subsection{Exponential models}

The above experiments were repeated to obtain the prediction equations in exponential form. Almost all post-landfall intensity decay models, e.g., those by Kaplan and DeMaria (1995), Vickery and Twisdale (1995), and Bhowmik et al. (2005), treat post-landfall decay of cyclones as an exponential function of time and cyclone structural parameters. In this experiment, we prepared the response variable/predictor set in the form given by equation (1). Even when the response variable was $\log (\mathrm{MSWL})$, the AIC values were computed by MSWL only, in order to make the results comparable to freeform models. For predictor set $\left\{\log \left(\mathrm{MSW}_{\mathrm{o}}\right), t, c\right\}$, only 27 models could satisfy AIC threshold, out of which, only four selected time as predictor. The fitness indices (equation 3) of exponential models were in general smaller compared to freeform models with similar predictors, showing weaker robustness of exponential models. The best exponential model showed AIC score of 297.4, and mean absolute error of 5.76. Similar to the case with freeform model, the best model did not show any dependency on post-landfall time span, $t$. For predictor set $\left\{\log \left(\mathrm{MSW}_{\mathrm{o}}\right)\right.$, IFL, $\left.c\right\}$, the results improved marginally with the best model scoring AIC value of 295.2. The best model, which selected all three predictors, showed a mean absolute error of $5.46 \mathrm{kt}$, but the same model showed large values of maximum error $(24.3 \mathrm{kt})$ and the number of cases (14) where error exceeded $10 \mathrm{kt}$.

\subsection{Selection of best model}

The results of above analysis are summarized in table 1. A general conclusion that appears from the above analysis is that the freeform empirical functions with predictor set $\left\{\mathrm{MSW}_{\mathrm{o}}\right.$, IFL,$\left.c\right\}$ appears to be more accurate (least mean absolute error) and robust (smaller maximum error and less cases with large errors) compared to exponential models. Further, post-landfall time seems to play a much weaker role in post-landfall intensity decay, compared to the amount of land intercepted by the storm and the forward motion speed of the cyclone, during the first few hours of landfall. The best empirical model (second equation in table 1) was worked out to be of the following form

$$
\begin{aligned}
\mathrm{MSW}_{\mathrm{L}}= & \mathrm{MSW}_{\mathrm{o}}+37.09 * \mathrm{IFL} /\left(\mathrm{MSW}_{\mathrm{o}}+6.93\right) \\
& -1.02 * c-0.94 * \mathrm{IFL} .
\end{aligned}
$$

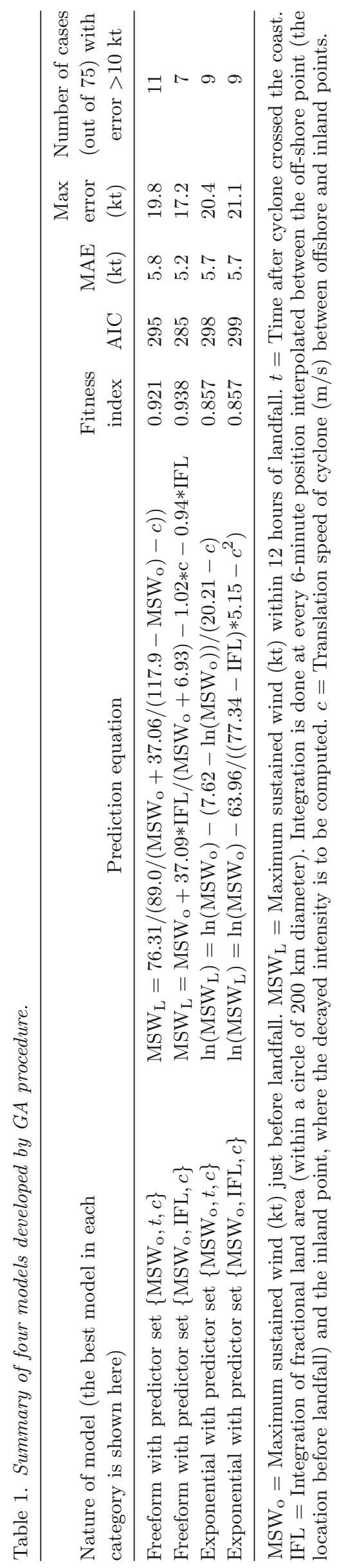


This model shows a linear dependency of decayed cyclone intensity on cyclone's forward speed and the amount of land surface intercepted by the storm during landfall. The predictors selected by the GA process appear to be physically meaningful and related to cyclone decay process. The second term in the right hand side of this equation containing reciprocal of $\mathrm{MSW}_{\mathrm{o}}$ is probably an adjustment term, which explains the fact that stronger cyclones decay faster than weaker ones during first few hours of landfall. The third term related to the translation speed of cyclone indicates a rapid decay for fast moving cyclones. This is consistent with the finding by other studies (Vickery 2005). The

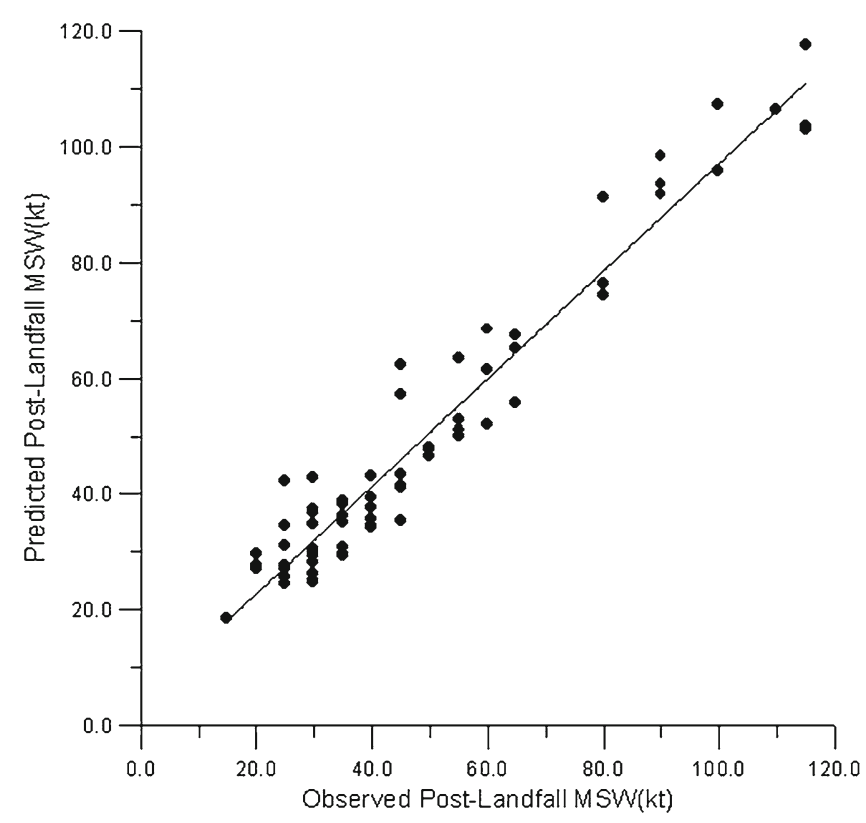

Figure 5. Comparison of predicted post-landfall intensities by best freeform model with observed values. Coefficient of determination $R^{2}$ is 0.938 . impact of IFL on decay process is slightly ambiguous in the above equation. IFL typically varies in the range 0.1-4.0. Thus for low intensity cyclones, the positive and negative terms linked with IFL almost balance each other. However, for high intensity cyclones, the negative term outweighs the positive term. This can also be interpreted as stronger influence of land on high intensity cyclones compared to weaker ones. Our forthcoming analysis (figure 7) shows that the impact of the land (indicated by IFL) decreases slightly as the cyclone intensity grows beyond $60 \mathrm{kt}$. For 25 high intensity $\left(\mathrm{MSW}_{\mathrm{o}}>64 \mathrm{kt}\right)$ cyclones, the mean absolute error of best free-form model was $6.0 \mathrm{kt}$, while the same for 50 low intensity cyclones $\left(\mathrm{MSW}_{\mathrm{o}} \leq 64 \mathrm{kt}\right)$ was found to be $4.8 \mathrm{kt}$. In general, post-landfall intensity predicted by the best prediction equation (second equation in table 1) shows high correlation $(r \sim 0.97)$ with the observed intensity (figure 5$)$.

\subsection{Analysis of model prediction errors}

Figure 6 shows the geographical distribution of prediction errors by best freeform model. Although, prediction errors are evenly distributed along the coastlines of the Bay of Bengal, one can notice that large errors are concentrated at few locations that include Bangladesh-Myanmar coast and east-central area of Indian peninsula. Tables 2, 3 and 4 respectively show the performance of the best model for cyclones of different intensity levels and over the basins where they made landfall. For cyclone 'NILAM', that made landfall on 31 October 2012 over the study region, the error for model predicted post-landfall intensity was $3.8 \mathrm{kt}$ (predicted $46.2 \mathrm{kt} v s$. observed $50 \mathrm{kt}$ ). It is to be noted that the largest basin-wise absolute error by the present model (6.3 kt over Myanmar coast) is

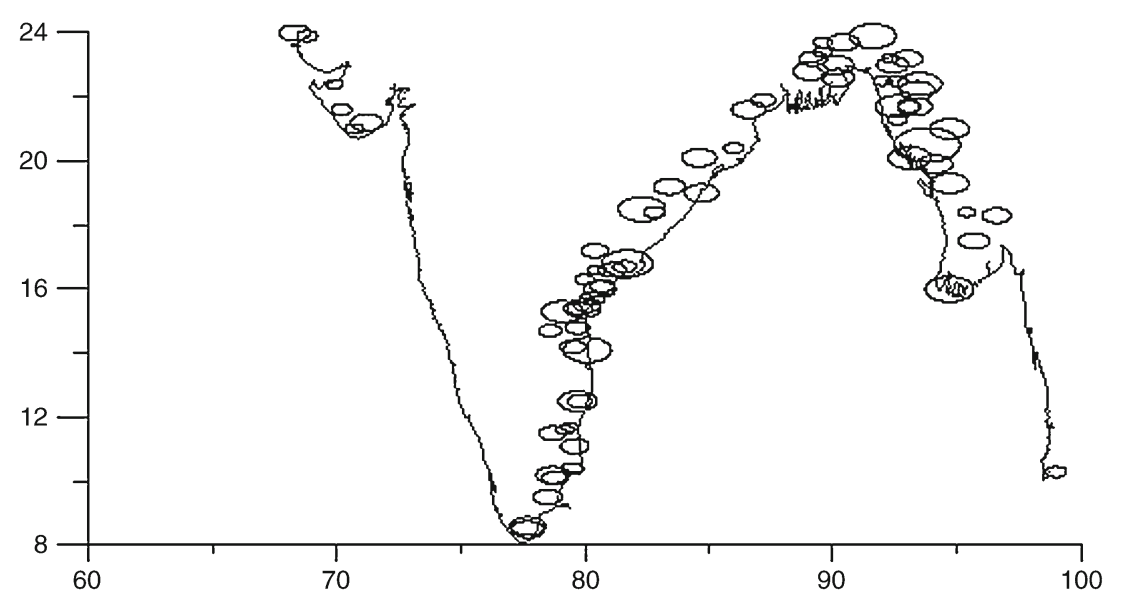

Figure 6. Geographical distribution of prediction errors by best freeform model. The size of circle represents the magnitude of error. Five points with large errors are shown by filled circles. The largest error is $17.2 \mathrm{kt}$. 


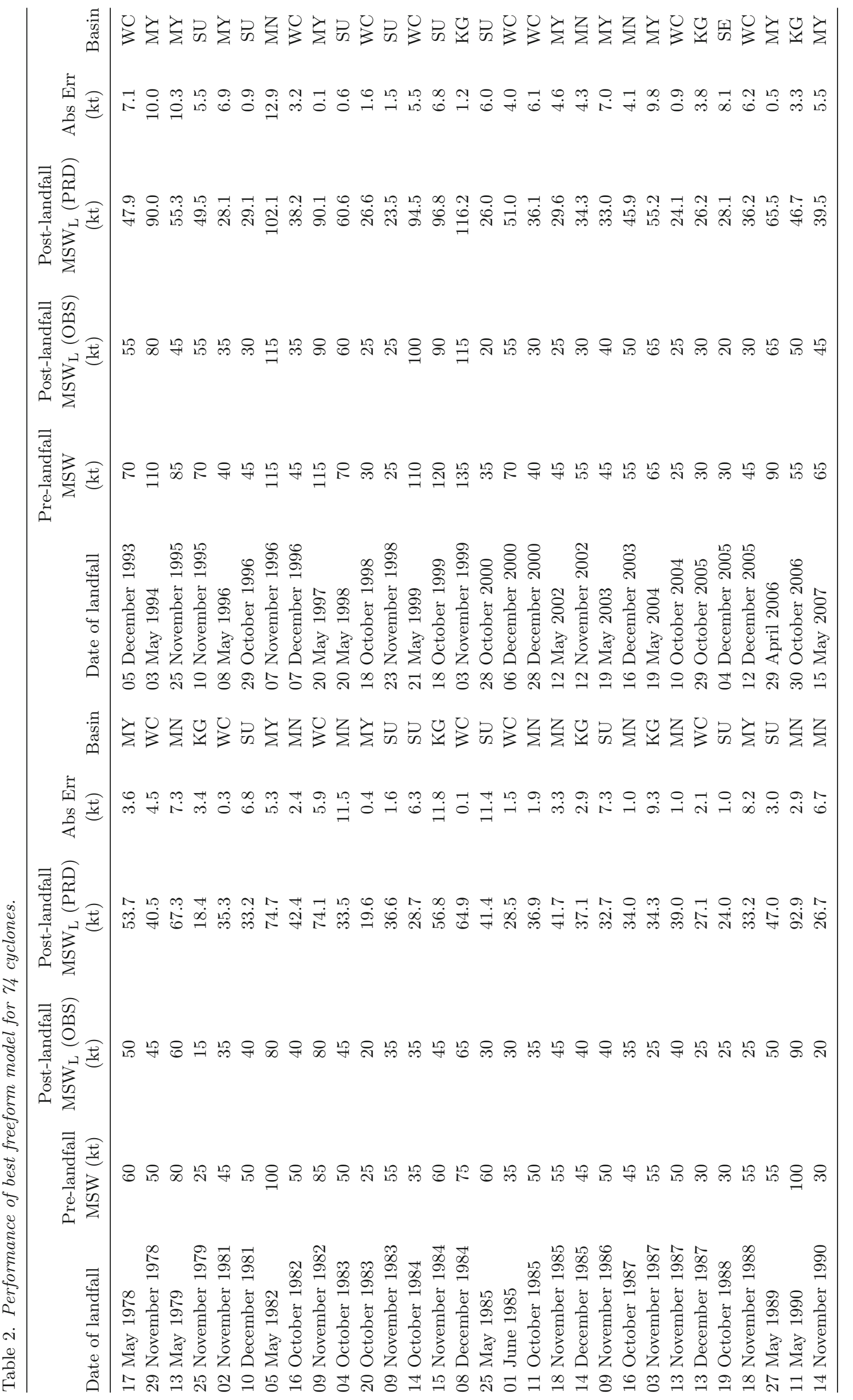


Table 3. Accuracy of best freeform model for cyclones in different categories.

\begin{tabular}{lccc}
\hline $\begin{array}{l}\text { Cyclone } \\
\text { category }\end{array}$ & $\begin{array}{c}\text { Intensity } \\
\text { range }\end{array}$ & $\begin{array}{c}\text { Number } \\
\text { of cases }\end{array}$ & $\begin{array}{c}\text { MAE } \\
(\mathrm{kt})\end{array}$ \\
\hline Depression & $<27 \mathrm{kt}$ & 4 & 1.6 \\
Deep depression & $28-33 \mathrm{kt}$ & 7 & 4.3 \\
Cyclonic storm & $34-47 \mathrm{kt}$ & 19 & 3.6 \\
Severe cyclonic storm & $48-63 \mathrm{kt}$ & 19 & 5.6 \\
Very severe cyclonic storm & $64-119 \mathrm{kt}$ & 20 & 6.3 \\
Super cyclone & $>120 \mathrm{kt}$ & 5 & 5.9 \\
\hline
\end{tabular}

Table 4. Same as table 2 but for cyclones making landfall at different coasts.

\begin{tabular}{lcc}
\hline Coastline & $\begin{array}{c}\text { Number } \\
\text { of cases }\end{array}$ & $\begin{array}{c}\text { MAE } \\
(\mathrm{kt})\end{array}$ \\
\hline West coast & 16 & 3.5 \\
Krishna-Godavari delta & 7 & 5.1 \\
Mahanadi delta & 14 & 4.9 \\
Sundarban delta & 14 & 4.6 \\
Myanmar coast & 20 & 6.3 \\
South-east India coast & 3 & 3.6 \\
\hline
\end{tabular}

comparable to the mean absolute error by other Indian Ocean models (e.g., $6.1 \mathrm{kt}$, Bhowmik et al. 2005). Absolute errors of the model over other basis are significantly smaller. Unaccounted regional factors like sea bathymetry, and temporal factors like ocean tidal oscillations can impact the cyclone intensification and decay processes close to the coast. Our future studies will try to include the impact of these factors with a view to develop more accurate intensity models.

Since the operational advisories and warnings related to tropical cyclones are updated at an interval of 6-hours, we assumed a constant TC translation speed $(c)$ during 6-hour interval. The methodology to compute the impact of assuming constant translation speed of cyclones during 6-hour interval has been provided in one of our earlier works (Patadia et al. 2004). Over the Indian Ocean, the assumption of constant speed would result in r.m.s. error of approximately $0.46 \mathrm{~m} / \mathrm{s}(10 \mathrm{~km} / 6-\mathrm{h})$. We simulated the impact of this error on the results of our best model and found that such assumption would lead to negligible impact on the performance of the model. Next we analyzed the sensitivity of the best model to translation speed and integrated landfill factor. Sensitivities were analyzed by computing the change in predicted intensity with a parameter of interest ( $c$ or ILF) is changed by $20 \%$ of its range. Figure 7 shows that predicted postlandfall intensities are not sensitive to IFL for low intensity cyclones (pre-landfall intensities $<30 \mathrm{kt}$ ). IFL sensitivity is maximum for severe cyclonic storms and reduces gradually as the cyclones grow 


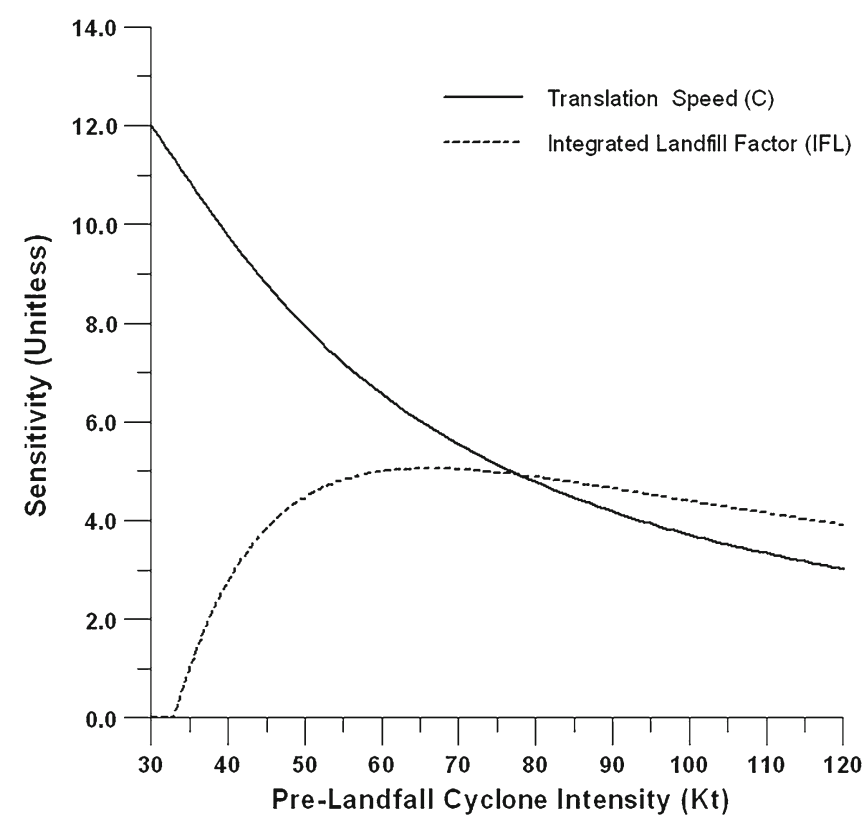

Figure 7. Sensitivity of predicted post-landfall intensity to (a) TC translation speed (solid line) and (b) integrated landfill factor (dashed line). (Sensitivity is defined as percentage change in intensity when a parameter is changed by $20 \%$ of its range with respect to its mean.)

stronger. On the contrary, the post-landfall intensities are most sensitive to translation speed for weak intensity cyclones and this sensitivity decreases with increasing pre-landfall intensity.

\section{Conclusions}

Using a nonlinear data-fitting algorithm and extended best track data (1992-2010), we tried to understand the nature of the tropical cyclone intensity change during the first 6-12 hours of landfall over the Indian Ocean region. Our analysis suggests that a specific freeform nonlinear model can explain the changes of cyclone intensity during landfall better than the exponential decay models. For an out of sample validation test, the mean absolute error of the prediction was found to be $5.2 \mathrm{kt}$, and a correlation of 0.97 . Our analysis indicates that time-integration of land area intercepted by cyclones during the landfall is a better predictor of post-landfall intensity compared to post-landfall time span. This approach also helps to tackle the complexity of coastline geometry of Indian subcontinent area.

\section{Acknowledgements}

The authors are thankful to the Joint Typhoon Warning Center, USA for providing free access to valuable best track datasets for the Indian Ocean cyclone. They are also thankful to the
United States Geological Survey (USGS) for valuable topography data used in the present study. Authors pay their sincere thanks to the reviewers for their valuable suggestions.

\section{References}

Akaike H 1974 A new look at the statistical model identification; IEEE Trans. Automat. Contr. AC 19 716-723.

Alvarez A, Orfila A and Tintore J 2001 DARWIN: An evolutionary program for nonlinear modeling of chaotic time series; Comp. Phys. Comm. 136 334-349.

Bender M A, Ginis I and Kurihara Y 1993 Numerical simulations of tropical cyclone-ocean interaction with a high-resolution coupled model; J. Geophys. Res. 98 $23,245-23,263$.

Bhowmik S K R, Kotal S D and Kalsi S R 2005 An empirical model for predicting the decay of tropical cyclone wind speed after landfall over the Indian region; J. Appl. Meteorol. 44 179-185.

Chang H, Niyogi D, Kumar A, Kishtawal C M, Dudhia J, Chen F and Mohanti U C 2009 Possible relation between land surface feedback and the post-landfall structure of monsoon depression; Geophys. Res. Lett. 36 L15826, doi: 10.1029/2009GL037781.

Chu J H, Sampson C R, Levine A S and Fakuda E 2002 The Joint Typhoon Warning Center Tropical Cyclone Best-Tracks 1945-2000; NRL Reference Number: NRL/MR/7540-02-16.

Colette A, Leith N, Daniel V, Bellone E and Nolan D S 2010 Using mesoscale simulations to train statistical models of tropical cyclone intensity over land; Mon. Weather Rev. 138 2058-2073.

DeMaria M, Knaff J A and Kaplan J 2006 On the decay of tropical cyclone winds crossing narrow landmasses; J. Appl. Meteorol. Climatol. 45 491-499.

Emanuel K A 1991 The theory of hurricanes; Ann. Rev. Fluid Mech. 23 179-196.

Ho F P, Su J C, Hanevich K L, Smith R J and Richards F P 1987 Hurricane climatology for the Atlantic and Gulf Coasts of the United States; NOAA Tech. Rep. NWS 38 195p.

Kaplan J and DeMaria M 1995 A simple empirical model for predicting the decay of tropical cyclone winds after landfall; J. Appl. Meteorol. 34 2499-2512.

Marks F, Shay L K and PDT-5 1998 Landfalling tropical cyclones - Forecast problems and associated research opportunities; Bull. Am. Meteorol. Soc. 79 305-323.

Patadia F, Kishtawal C M, Pal P K and Joshi P C 2004 Geolocation of Indian Ocean tropical cyclones using $85 \mathrm{GHz}$ observations from TRMM Microwave Imager; Curr. Sci. 87 504-509.

Pielke Sr R A 2001 Influence of the spatial distribution of vegetation and soils on the prediction of cumulus convective rainfall; Rev. Geophys. 39 151-177.

Pielke Sr R A and Niyogi D 2010 The role of landscape processes within the climate system; In: Landform Structure, Evolution, Process Control: Proceedings of the International Symposium on Landforms organised by the Research Training Group 437 (eds) Otto J C and Dikaum R, Lecture Notes in Earth Sciences, Springer-Verlag Berlin Heidelberg, 115, doi: 10.1007/978-3-540-75761-0_5

Sclove S L 1987 Application of model-selection criteria to some problems in multivariate analysis; Psychometrika 52 333-343.

Tuleya R E 1994 Tropical storm development and decay: Sensitivity to surface boundary conditions; Mon. Weather Rev. 122 291-304. 
Vickery P J 2005 Simple empirical models for estimating the increase in the central pressure of tropical cyclones after landfall along the coastline of the United States; J. Appl. Meteorol. 44 1807-1826.

Vickery P J and Twisdale L A 1995 Wind-field and filling models for hurricane wind-speed predictions; J. Struct. Eng. 121 1700-1709.
Vickery P J, Masters F J, Powell M D and Wadhera D 2008 Hurricane hazard modeling: The past, present and future; J. Wind Eng. Industrial Aerodynam. 97392 405.

Wong M L M and Chan J C L 2006 Tropical cyclone motion in response to land surface friction; J. Atmos. Sci. 63 1324-1337.

MS received 5 April 2012; revised 1 February 2013; accepted 5 February 2013 